\title{
LAS INTERACCIONES PROFESOR-ESTUDIANTES: FUNDAMENTO DE LA FORMACIÓN EN LAS PROFESIONES ${ }^{1}$
}

\author{
CONSUelo GutiéRREZ De GonZÁLEZ* \\ Carlos Eduardo Vasco Uribe**
}

Recebido em: 05 de fevereiro de 2008

Aprovado em: 12 de dezembro de 2008

\begin{abstract}
*Mg. Ciencias económicas, Profesora-investigadora de la Maestría en Educación de la Universidad Javeriana de Bogotá, Colombia, en las líneas de Procesos formativos en Educación superior y Política y Gestión de Sistemas educativos.

E-mail: alcon@cable.net.co

** Ph.D. en matemáticas, profesor emérito de la Universidad Nacional de Colombia, Presidente del Consejo de Doctores del Doctorado en Ciencias Sociales, Niñez y Juventud, Universidad de Manizales-CINDE.
\end{abstract}

Resumen: Reconociendo los retos que en cuanto a la formación profesional enfrenta la universidad de hoy, en el presente ensayo se proponen las interacciones profesor-estudiantes como núcleo de la formación, cuyo estudio ha de aportar luces para una reconstrucción creativa y fructífera de los procesos educativos orientados a la generación de profesionales idóneos y con sentido ético y de identidad personal. Se parte de la tesis de que las interacciones formativas se configuran por dos determinantes: de un lado, por la lógica, estructura y dinámica internas de la profesión misma y sus relaciones con otras profesiones y, de otro, por las concepciones, intencionalidades y actos de los actores en su interacción cotidiana. La interacción, en este contexto, tiene como finalidad la formación profesional; de allí que se haga necesario recuperar el concepto de Bildung como depositario de una tradición que ha identificado y aún identifica el lugar de la universidad en la sociedad, pero no sólo como una formación "en cultura general" sino como una formación integral configurada desde la profesión específica en la cual se forma el estudiante. Luego de ello se pasa a fundamentar y describir una propuesta metodológica para el estudio de las interacciones educativas en las profesiones, que puede ser útil para la realización de análisis empíricos sobre el tema que sirvan a su vez de fundamentos para el diseño curricular y didáctico, así como para las construcciones pedagógicas en el marco de la formación profesional.

Palabras clave: Formación profesional. Interacción profesor-estudiantes. Formación integral. Construcciones pedagógicas.

\section{TEACHER-STUDENT INTERACTIONS: THE BASES OF EDUCATION IN PROFESSIONAL TRAINING}

\begin{abstract}
Recognizing the challenges that higher education faces in today's university, the present article proposes teacher-student interactions as the nucleus of education, whose study will bring light to a creative and fruitful reconstruction of the educative processes oriented towards developing capable and ethical professionals with a sense of personal identity. It is based on the belief that the educational interactions are formed by two determinants: on one hand, by the internal logic, structure and dynamic of the profession and its relations with other professions and, on the other hand, by the concepts, intentions and actions of the actors in their daily interaction. The interaction, in this context, has the purpose of professional training; from there it is necessary to recover the concept of Bildung as a repository of a tradition that is identified as and also identifies the place of the university in society, not only as a "general knowledge" education, but also as
\end{abstract}

1 Este artículo fue elaborado, en principio, como ponencia doctoral alterna para el programa de Ciencias Sociales, niñez y juventud de la Universidad de Manizales y el CINDE, Colombia, bajo la tutoría del Dr. Carlos Eduardo Vasco. 
a well rounded education, shaped from the specific major chosen by the student. As a result, a methodological proposal to study the educational interactions in the professions is made, a method that can also be useful to empirical analyses on the topic that serves as foundation both for the didactic and curricular design, as well as for the pedagogical constructions in the context of higher education.

Key words: Profesional training. Teacher-student interations. Rounded education. Pedagogical constructions.

\section{Introducción}

La formación profesional, uno de los vínculos que por tradición y de manera más clara ha unido a la universidad con la sociedad, se hace, en este momento, especialmente problemática debido, de un lado, a las urgentes demandas que le plantea la sociedad y, de otro, a la expansión de los cuerpos teóricos y de prácticas que nutren las profesiones. La universidad se ve entonces urgida a replantear sus procesos de formación profesional, tratando a la vez de responder a lo que exige el cambiante entorno y de organizar el cúmulo creciente de conocimientos que produce, difunde y transmite.

En nuestro medio se ven claras manifestaciones de esta situación. El establecimiento oficial de los contenidos propios de cada programa académico, mediante la promulgación de los estándares mínimos de calidad de parte del Ministerio de Educación, puede entenderse como un intento de fijar los límites $\mathrm{y}$ fronteras profesionales en un momento en que estos tienden a difuminarse. En otro sentido, la discusión actual en torno a la organización de la educación superior y sobre el carácter ideal -básico o aplicado- del pregrado, es también indicio de la situación de incertidumbre que atraviesa hoy día la academia en relación con la formación profesional para las ocupaciones específicas, que tendería a configurarse en otros espacios diferentes al pregrado, como los estudios de postgrado o, incluso, en el propio ámbito laboral, lo que implica una profunda transformación del papel de la universidad y de su relación con otras instancias sociales.

Debido a lo anterior, los temas pedagógicos, curriculares y didácticos asumen ahora inusitada eminencia en la gran mayoría de programas universitarios, los que instan a directivos académicos y profesores a mantener una continua actualización y reflexión en estos aspectos, con el propósito de lograr una "mejor formación de los educandos”. A pesar de ello, parece olvidarse con frecuencia que los planteamientos curriculares, pedagógicos y didácticos formulados por las instituciones se concretan en el aula, no entendida como espacio físico, sino como referente del hecho social que da sustento al proceso educativo en su conjunto y asegura la pervivencia de la profesión: la interacción formativa 
entre profesor y estudiantes. Por ello, tal interacción debe ser asumida como objeto de análisis para la construcción de las propuestas formativas en las profesiones. Ello requiere detenerse a considerar tanto los componentes de dicha interacción como su referente más amplio: la profesión, en la que encuentra sentido y hacia la cual se dirige. Además, es necesario recuperar el carácter distintivo de esta interacción, su intencionalidad formativa, que la integra a una tradición que es oportuno retomar en este lugar para no perder de vista los más altos fines de la educación superior.

En el presente trabajo se parte de la tesis de que la estructura y la dinámica del proceso formativo, constituido por las interacciones profesor-estudiantes, en cada profesión están indisolublemente ligadas a la naturaleza conceptual y técnica de ésta, así como a su posición relativa dentro del campo de las profesiones y del trabajo especializado. Por ello, resulta desatinado tratar de configurar el proceso formativo de acuerdo con metodologías generales, ajenas en principio a la singularidad de cada profesión. Se requiere, al contrario, penetrar en la lógica intrínseca a cada una, para trazar, desde el interior mismo de esta lógica conceptual y práctica, las vías idóneas para su apropiación y desarrollo de parte de cada estudiante. Esto requiere, además del análisis lógico y epistemológico de los contenidos, una detenida consideración de los procesos interactivos que ocurren en la cotidianidad de la formación profesional en cada programa educativo específico, en los cuales, otra vez, cobran importancia central el profesor y el estudiante, como agentes fundamentales del proceso formativo que se realiza en la inmediatez de la interacción sostenida entre ambos.

De la anterior tesis emanan algunas consecuencias de interés inmediato para la práctica formativa universitaria, de las cuales mencionaremos aquellas a nuestro juicio más relevantes. En primer lugar, implica que el tan promocionado carácter 'integral' de la formación no se deriva en exclusiva de la adición de contenidos 'humanísticos' a los programas lectivos de los estudiantes con el argumento de incrementar su 'cultura general'; el núcleo de una formación que comprometa la totalidad del ser del estudiante reside en lo que es propio de la profesión que estudia y que ejercerá identificándolo ante la sociedad. Esto significa que cada profesión, además de sus particulares constelaciones conceptuales y técnicas, establece ciertas formas de ser humano, de concebirse a sí mismo y el propio lugar en el mundo social. Es, pues, en los mismos espacios de formación en la carrera de su elección, donde el joven sujeto cuenta con las mayores oportunidades para desarrollar los elementos necesarios para la consistente construcción de su identidad. En segundo lugar, la tesis implica que este proceso, de carácter por completo social, requiere de la participación 
protagónica del otro actor fundamental del ejercicio formativo: el profesor, quien tradicionalmente ha cumplido un papel de referente profesional y ético para los jóvenes, papel que ahora tiende a olvidarse, encubierto por una concepción de claro acento funcional que ha opacado la relevancia de la interacción profesorestudiante como forma particular de relación humana, dirigida a la construcción de la subjetividad del otro. Vale resaltar aquí que aunque la subjetividad que se privilegia en su construcción es la del estudiante, la perspectiva aquí planteada implica que el profesor también se transforma en el curso del proceso, en tanto que no puede dejar de implicarse en su propia subjetividad si quiere dar lugar que la interacción se convierta un auténtico proceso formativo que trascienda lo técnico de la enseñanza.

A partir del anterior reconocimiento de las interacciones profesor-estudiantes como núcleo del proceso académico de formación, resulta evidente que su estudio ha de aportar luces para una reconstrucción creativa y fructífera del conjunto de los procesos educativos, así como para la generación de profesionales idóneos y con sentido ético y de identidad personal, competentes para la participación transformadora de la sociedad. Dicho estudio ha de tener en cuenta, en primer lugar, la profesión, como marco de referencia determinante de la interacción, incluyendo su lógica, estructura y dinámica y, luego, el proceso mismo de interacción, el que se caracteriza en términos de concepciones, intencionalidades y actos. La interacción, en este contexto, tiene como finalidad la formación, tercer referente a estudiar, lo cual implicará la recuperación del concepto de 'Bildung' como depositario de una tradición que, aunque amenazada hoy, no debe ser desestimada por la universidad, pues ella constituye parte importante de aquello que en el transcurso de la historia ha sido eje de su identidad y ha definido su papel como agente recreador de la sociedad. Cabe aclarar que estos tres objetos del análisis, profesión, interacción y formación, están en estrecho anudamiento, pues mientras profesión y formación son descritas según dimensiones similares que expresan la correspondencia entre una y otra, la interacción es fundamento de la formación en las profesiones, lo que no debe olvidarse al distinguir, para fines de la exposición, cada uno de estos conceptos.

Se pasa luego a fundamentar y describir una propuesta metodológica para el análisis de las interacciones formativas entre profesor y estudiantes de programas universitarios profesionales, dirigida a proveer un marco para la observación y comprensión de estos procesos, lo que constituye un insumo fundamental para el desarrollo curricular y didáctico de modalidades de formación que atiendan tanto al ser, el saber y el hacer de los futuros profesionales, según las cualidades inherentes a las diversas profesiones. El enfoque de análisis 
propuesto ha sido ensayado en varios estudios exploratorios, a través de los cuales se ha ajustado y depurado, y cuyos resultados ofrecen evidencia acerca de los planteamientos que aquí se realizan.

\section{La Profesión como Realidad Institucional y Subjetiva}

Iniciaremos, entonces, las consideraciones teóricas sobre los componentes de las interacciones formativas profesor-estudiantes en la educación superior tratando de especificar la construcción institucional y cultural (e incluso subjetiva, como se verá) en la que se enmarcan y les otorga sentido: la profesión. Para tal fin conviene empezar por preguntarse qué se entiende, en general, por profesión. El vocablo "profesión" proviene del latín pro-fateor, que significa dar a conocer públicamente o comunicar lo que uno es y lo que uno hace para servir a la sociedad (BORRERO, 2006). Según el Diccionario de la Real Academia Española (edición del año 2001), se deriva del verbo “profesar”, el cual indica el ejercicio de una ciencia, arte u oficio o la enseñanza de las mismas, a lo que el término "profesión" añade el hecho de recibir una retribución por estas actividades. También reviste el vocablo una acepción de tipo más subjetivo, en el sentido de las creencias o afectos mantenidos "con inclinación voluntaria y continuación”, como cuando se dice "profesar una fe o una doctrina”. De manera más general, "profesar” puede referirse a "algún afecto, inclinación o interés, y perseverar voluntariamente en ellos”.”En el ámbito de la institución religiosa, se refiere a "obligarse a cumplir los votos" que establece cada organización a sus miembros como normas de conducta. Puede notarse desde ya que el término "profesión" involucra entonces no sólo la actividad técnica, el mero Hacer, sino también ciertas disposiciones del sujeto en su relación general con el mundo social, que configuran una ética, un modo de Ser, lo que, por supuesto, incluye el Ser-en-relación, proyectándose hacia la comunidad, aspecto que no por casualidad está tratando de recuperarse en el presente por los grupos profesionales en la búsqueda de una identidad y una clara norma de conducta. De manera implícita, como presupuesto necesario para la puesta en práctica de la actividad u oficio que se ejerce, así como para la adscripción a ideas religiosas o de otra índole, subyace al término "profesión" la dimensión del Saber, la cual, dentro del contexto académico, tiene una relevancia medular. Ser, Saber y Hacer, se perfilan desde estas definiciones preliminares, como dimensiones constitutivas de la profesión; en lo que sigue se desarrollarán éstos con mayor amplitud. 


\section{La Edad media: origen de las profesiones universitarias}

Un rasgo de las profesiones, como se entienden en la actualidad, es su estrecho vínculo con la institución universitaria, que si bien no es ni ha sido la única encargada de la formación profesional, constituye un caso paradigmático de este tipo de formación en la que funda gran parte de su razón de ser. Es en relación con la universidad y con la formación que en ella tiene lugar, donde el término profesión asume su carácter más distintivo, consolidado por la larga historia compartida desde el origen de la institución en la Edad Media. Con la universidad nació una nueva forma de concebir el conocimiento y su relación con la práctica; aquella que encarnaron las profesiones de teología, derecho y medicina. Fuera de aquellas profesiones, toda ocupación era considerada, entonces, un mero oficio (GOLDSTEIN, 1984). La novedad estaba en que, de una parte, estas profesiones primigenias se nutrían de un vasto cuerpo de conocimientos codificado, sistemáticamente conservado y transmitido por la institución universitaria, $\mathrm{y}$, de otra parte, se referían a aspectos de vital importancia social: los teólogos eran los encargados de la vida espiritual y, en tal sentido, dominaban el conocimiento más valioso y amplio de la época, cuya posesión los hacía idóneos legitimadores de la poderosa institución religiosa y, en general, ofrecían sustento simbólico a todo el orden social; los doctores en leyes se ocuparían de la adecuada administración del poder secular y de los negocios públicos de las nacientes ciudades-estado donde surgieron las primeros centros universitarios; por último, los profesionales en medicina velarían por la curación de enfermedades. (BORRERO, 2006)

La universidad generó, pues, desde su mismo origen, una particular simbiosis entre producción, conservación y transmisión institucionalizada del saber y su uso con relevancia social, la cual todavía hoy impregna el ejercicio académico y el concepto mismo de profesión. Así pues, la historia de las profesiones está en gran medida entrelazada con la historia de la institución universitaria; ambas son creaciones socioculturales del mundo occidental que desde fines de la Edad Media, a lo largo de toda la modernidad y hasta el presente han dado forma a dos importantes componentes de la cultura: el saber y la aplicación de éste como mediador de la relación del ser humano con su entorno físico y social. Aunque desde el siglo XIX se han creado diversas modalidades institucionales con fines de transmisión de conocimiento especializado, es la universidad el prototipo y sigue siendo el principal referente para comprender estos procesos, sobre todo porque los incluye dentro de una concepción epistemológica integral. Así pues, la profesión ha sido el espacio de los sujetos que - gracias al saber 
- desarrollan acciones especializadas sobre el mundo natural o institucional, mientras que la universidad ha sido el espacio propio de producción de ese saber y sigue siendo uno de los más relevantes de los dirigidos a la formación de esos sujetos.

Por supuesto, universidad y profesión han experimentado gran variedad de cambios a lo largo de la historia, en relación con la transformación de las sociedades y de los fines que cada una de éstas fijaba para el conocimiento y su aplicación. No es este el espacio para la indagación detallada de tales mutaciones. Se dedicará, más bien, a definir una caracterización comprensiva de las dimensiones de la profesión que permita abordarla en los distintos planos que involucra y ponerla en relación con los otros dos términos que articulan el presente discurso: interacción y formación. Al respecto, reiteramos aquí que la profesión es un complejo que abarca tres dimensiones inseparables, son ellas el Ser, el Saber y el Hacer, a lo que agregamos ahora que no se refieren con exclusividad a atributos del individuo, sino que, como se verá, designan a la vez aspectos definitorios de la institución social conocida como profesión. Es, de hecho, la posibilidad de una correspondencia entre el nivel individual y el social, uno de los aspectos que la presente propuesta trata de afianzar.

\section{Las tres dimensiones de la profesión}

El análisis de la profesión en los mencionados términos será llevado a cabo siguiendo la formulación presentada por Gardner y cols. en dos de sus más recientes obras, Buen Trabajo - Good Work - (2001/2002) y Making Good (2004), en las que se realiza uno de los abordajes más sistemáticos del concepto de profesión emprendidos en tiempos recientes, distinguiendo tres esferas que integran el universo profesional: el dominio (domain), el campo (field) y los profesionales individuales o personas (self), los cuales admiten una correspondencia con las tres dimensiones aquí planteadas (en el orden Saber, Hacer y Ser). La caracterización de la profesión será presentada, en consecuencia, siguiendo tales dimensiones y estableciendo un diálogo entre éstas, la propuesta de Gardner y cols., así como con otras perspectivas teóricas que pueden aportar a la formulación.

- Saber: Toda profesión involucra un acervo simbólico que le es propio y característico. Producción teórica y conocimiento técnico instrumental para la intervención en la realidad, pero también pautas de conducta, valoracio- 
nes y criterios prácticos hacen parte del cúmulo de bienes intelectuales que caracterizan cada profesión y con respecto a los cuáles ésta organiza su acción al recuperarlos, conservarlos, transmitirlos y transformarlos. Esta caracterización es próxima a lo que Gardner y cols. llaman dominio (domain); aquel componente que se encuentra conformado por la misión a largo plazo y los objetivos implicados en una labor profesional, casi inalterables con el transcurso del tiempo.

Por ejemplo, en la ciencia, el término designa un conjunto específico de metas y aspiraciones: observar el mundo detalladamente, desarrollar teorías y conceptos apropiados, llevar a cabo experimentos cuidadosamente, replicar los resultados, reportar hallazgos públicamente y debatir su significado. (GARDNER et al., 2004. p. 17)

Un dominio, en la formulación citada, comprende, entonces, los lineamientos filosóficos de una profesión y como tal, pertenece al ámbito de lo simbólico. Asimismo, incluye el saber o conocimiento necesario para ejercer una profesión, codificado como sistema simbólico y, por consiguiente, transmisible:

Cuando se ha codificado el conocimiento especializado lo suficiente para que se pueda transmitir sin problemas a los nuevos profesionales, al sistema simbólico resultante le llamamos dominio. (GARDNER et al., 2002, p. 41)

En síntesis, el dominio se refiere a la dimensión simbólica o cultural de una profesión, al saber que la distingue, tanto en lo referente a conceptos, teorías y métodos, como códigos y principios de actuación que se consideran característicos de tal profesión. El saber, como aquí lo definimos, excede el ámbito de lo teórico. En ese sentido coincide con el proyecto de sociología del conocimiento de Berger y Luckmann, quienes entienden éste como todo cúmulo de elaboración simbólica del mundo social que permite a los individuos actuar con eficacia en éste. Desde esta perspectiva, el rol, por ejemplo, es visto como la decantación de cierto sector del total de conocimiento social útil para el ejercicio de determinadas funciones, conocimiento no sólo técnico o teórico, sino también actitudinal y valorativo, así, por ejemplo,

Ser juez implica, a todas luces, un conocimiento del derecho y probablemente también de una gama mucho más amplia de los asuntos humanos que tienen relevancia legal. Implica, asimismo, un conocimiento de los valores y actitudes que se consideran propios de un juez [... también debe poseer un conocimiento apropiado en el terreno de las emociones. (BERGER; LUCKMANN, 1968, p. 101) 
Hemos hablado de saber, pero al mencionar la obra de Berger y Luckmann ha entrado el término 'conocimiento'. Se trata del reflejo de una bifurcación terminológica entre el mundo anglosajón, desde el que escriben los autores citados, que prefiere el vocablo conocimiento, y la Europa continental, donde se prefiere el término 'saber', que ha logrado mayor protagonismo en las ciencias de la educación y que preferimos, además, por enunciarse como el infinitivo de un verbo que da idea de un proceso activo, en permanente puesta en práctica.

- Hacer: La profesión es también, con inmediata evidencia, una práctica. Una acción dirigida y organizada de los individuos orientada a ciertos propósitos de relevancia reconocida, que recaen sobre el mundo social, cultural o natural, según la guía del saber, con lo que se muestra ya la inextricable relación entre las dimensiones identificadas. Pero además del ejercicio experto como tal, la profesión involucra otro tipo de acciones que también la caracterizan: la actividad gremial, la enseñanza, las iniciativas comunes para obtener reconocimiento social, son ejemplos de ello. La noción de campo (field) de Gardner et al., permite acercarse a esta dimensión. Al definirlo como el conjunto de instituciones e individuos que encarnan el dominio en un momento histórico particular, el campo es la expresión concreta del dominio en el ámbito de lo humano:

Como conjunto de símbolos, los dominios sólo existen como ideas y valores [...] Para convertirse en reales, deben estar representados por personas [...] es lo que denominamos campos, es decir, los hombres y mujeres que realmente practican los procedimientos de un dominio." (GARDNER et. al., 2002, p. 43)

Pero al referirse a los individuos, estos autores los entienden en términos de su organización colectiva y del lugar que cada uno ostenta dentro de ella. Así, un campo profesional se compone de distintas clases de individuos: los guardianes o legitimadores del mismo, los expertos o reconocidos por los guardianes como idóneos para ejercer, y los aprendices o estudiantes. Si bien -como lo anota Vasco (2006, p. 207-208) - la mirada de Gardner et al. En algunos pasajes (ver GARDNER et al, 2002, p. 43) se centra en el papel de los individuos, puede notarse también a través de otros escritos el componente social de la profesión, su carácter de institución, en la que existen estatus, roles, normas y funciones (ver, por ejemplo, el resumen en GARDNER et al., 2002, p. 46, y el cuadro propuesto por el mismo GARDNER en la p. 324 de SCHALER, 2006). En términos de la sociología comprensiva, los profesionales son 
portadores del complejo de significados de la profesión, el que actualizan con cada una de sus acciones profesionales. En tal sentido también puede ligarse el campo con el Hacer en el que se realiza en cada circunstancia la profesión, que sin la actuación de los profesionales, perdería su carácter de profesión y se reduciría a diletante ilustración.

La denominación que emplean los autores es sugerente, además, porque nos remite a la tarea de contrastar este concepto de campo con la idea que ofrece Bourdieu sobre el mismo término y que puede ser útil para complementar la visión de este aspecto sociológico de la profesión. Según el intelectual francés, hace referencia a "[...] un campo de fuerzas, dotado de una estructura, así como un campo de luchas para conservar o transformar ese campo de fuerzas." (BOURDIEU, 2003, p. 64). Con esto se recuerda que, como toda otra configuración social, la profesión es escenario de conflictos entre los intereses de sus actores, por cuanto todos se dirigen a acaparar el mayor volumen posible de capital, entendido no sólo en tanto que medios económicos, sino como cualquier recurso, con frecuencia simbólico, como el saber y el prestigio a éste asociado, que implique la superioridad de unos agentes sobre los otros dentro del contexto del campo: "la estructura de la distribución del capital, determina la estructura del campo, es decir, la relaciones de fuerza entre los agentes

[...] el control de una cantidad (y, por tanto, de una parte) importante de capital, confiere un poder sobre el campo, y, por lo tanto, sobre los agentes menos dotados (relativamente) de capital (y sobre el derecho de admisión en el campo), y dirige la distribución de las posibilidades de beneficio. (BOURDIEU, 2003, p. 66)

Las tendencias intrínsecas de unos a mantener sus privilegios y de otros a conquistarlos alimentan el permanente estado de conflicto al interior del campo, que como tal implica formas de violencia, si bien ésta por lo común no es abierta y explícita sino de carácter simbólico, dado que en el mismo campo se establecen las pautas que regulan las pugnas, determinando lo que es aceptable y lo que no para hacerse al poder:

[...] campo de lucha, campo de acción socialmente construido, en el que los agentes, dotados de recursos diferentes, se enfrentan para conservar o transformar las correlaciones de fuerza existentes. Los agentes desencadenan unas acciones que dependen en sus fines, sus medios y su eficacia, de su posición en el campo de fuerzas, es decir, de su posición en la estructura de distribución del capital. (BOURDIEU, 2003, p. 67) 
No es, pues, el campo profesional una comunidad idílica; en éste, como en cualquier otro, los individuos pretenden posicionarse y obtener un estatus de superioridad sobre sus iguales, y, una vez agenciado éste, tratar de configurar las pautas de funcionamiento del campo de la manera que más convenga a sus intereses. Es éste uno de los más fuertes motivos de la dinámica que mantienen las profesiones en transformación histórica constante.

- Ser: La profesión, ya como complejo simbólico, ya como estructura institucional, sólo se hace real en individuos, para quienes la profesión ha de ser una realidad que los comprometa de manera intensa: la fuente de su identidad. Al incluir conocimientos teóricos y técnicos, actitudes y valoraciones, en tanto que Saber; mientras que como Hacer remite a posiciones en la estructura social, a ciertas pautas esperadas de conducta, además de expectativas y estrategias para lograrlas, la profesión colma al individuo con sus múltiples determinaciones. A ello Gardner y cols. (2004) lo llaman Persona (self), término de honda raigambre en la tradición psicológica norteamericana que aquí se refiere, por un lado, a un complejo de experticia, personalidad, temperamento, creencias y valores, por el otro, a experiencias clave, especialmente de aquellas que son experimentadas por el individuo mismo como transformadoras. Se trata de una dimensión imprescindible para definir la identidad de una profesión, ya que "Las profesiones surgen cuando un grupo de profesionales individuales definen los conocimientos, las destrezas, las prácticas, las normas y los valores específicos que les diferencian del resto de la cultura." (GARDNER, et al. 2002, p. 40). En el radio de acción que establece la persona profesional, se pueden distinguir varios tipos de relaciones: las que se establecen con otros individuos con quienes se mantienen vínculos íntimos y estrechos y quienes juegan un rol relevante en el desarrollo del yo; las de tipo vertical con profesores, mentores, antimentores - modelos negativos de rol - y parangones - modelos desconocidos personalmente - ; las horizontales con los pares y las establecidas con el propio sistema de valores. Dado que se refiere a la subjetividad del individuo, a la forma cómo el ejercicio de la profesión configura su identidad, puede decirse que esta esfera se refiere al Ser, mostrando cómo la profesión no es un mero cúmulo de conocimientos y un repertorio de técnicas, sino una forma particular de ser humano en una sociedad y época determinadas: el sentido subjetivo que cada persona da a su actuar en el mundo, lo que implica, al decir de Giddens (citado por CASTELLS, 1999): “comprender [...] tanto lo que se está haciendo, como por qué se está haciendo". 
De acuerdo con lo dicho, podría sintetizarse la caracterización de profesión aquí presentada como sigue: una profesión es una configuración institucional en la que tiene lugar una intersección compleja de tres dimensiones tradicionalmente invocadas en las discusiones sobre tópicos relacionados con la formación, y cuya presencia puede colegirse de muchas de las concepciones expuestas en la revisión del concepto. Dichas dimensiones son Ser, Saber y Hacer, siempre intrincadamente ligadas y que constituyen la estructura institucional de la profesión. En este sentido resulta coherente retomar el concepto de institución, como lo entendieron Berger y Luckmann (1968), de acuerdo con los cuales, las instituciones sociales, "tipificación recíproca de acciones habitualizadas por tipos de actores", comportan cúmulos de conocimiento relevante, así como normas y prescripciones sobre los conjuntos de funciones (roles) que han de cumplir los actores, los que en tal proceso desarrollan identidades específicas ligadas a esos roles. El conocimiento relevante constituye el Saber de la profesión, mientras que el Hacer tiene que ver con las pautas que regulan las funciones del rol profesional. El Ser se refiere a la identidad construida en este ámbito institucional a partir de tales elementos. Ahora bien, toda institución tiende a asegurar su permanencia, desarrollando para ello mecanismos de reproducción basados en la interacción social, la que se hace así el fundamento de la vida histórica de las instituciones, otorgándole a éstas su pervivencia, así como facilitando su transformación en relación con las mutaciones del orden social más amplio. Pasaremos, en consecuencia, a estudiar la interacción en tanto que proceso generador de la institución profesional como realidad objetiva y subjetiva para los sujetos que en ella están implicados, lo que servirá como marco para la comprensión de esa modalidad específica de interacción que le es propia: la formación profesional.

\section{La Interacción Social como Constructora de Realidad Institucional}

En el sentido en que hasta este punto se ha descrito, la profesión aparece como un medio por el cual las sociedades modernas logran generar sujetos (implicando el Ser de éstos) competentes para su reproducción y desarrollo en el tiempo (por medio de particulares formas de Hacer), mediante la objetivación y la internalización de los acervos de conocimiento harto sofisticados que son patrimonio de estas sociedades (la dimensión de Saber). La manera en que esto tiene lugar implica, siguiendo a Berger y Luckmann, considerar los procesos de interacción que posibilitan la realidad institucional, la cual se 
establece gracias a una continua dialéctica entre la faceta objetiva y la faceta subjetiva de la vida social, o dicho de otro modo, entre la facticidad de su configuración institucional y la experiencia subjetiva. A la vez que las instituciones dan forma tanto a la acción como a la biografía de los individuos, éstos, en su acción - y particularmente en su interacción - cotidiana, dan vida a aquéllas, asegurando su permanencia en el tiempo, y abriendo las posibilidades de su transformación histórica: “Con todo, ya es posible advertir la relación fundamental de estos tres momentos dialécticos de la realidad social [...]. La sociedad es un producto humano. La sociedad es una realidad objetiva. El hombre es un producto social." (BERGER; LUCKMANN, 1968, p. 84). El escenario donde se dinamiza esta dialéctica no es otro que el de la vida cotidiana, lo que en el caso aquí tratado se refiere a la interacción profesor-estudiantes en los espacios formativos universitarios.

Según esta mirada, para la comprensión de las instituciones universitaria y profesional, reviste especial relevancia considerar la internalización de los acervos de conocimiento que tienen lugar en el proceso de socialización secundaria, posterior a la formación del Yo debida a la socialización primaria en los inaugurales años de vida del individuo. La socialización secundaria que se extiende desde la niñez hasta el final de la vida se refiere a "la internalización de submundos institucionales o basados en instituciones [...] es la adquisición del conocimiento especializado de 'roles', estando éstos directa o indirectamente arraigados en la división del trabajo” (BERGER; LUCKMANN, 1968, p. 175). Los submundos institucionales, denominados así por su relación subsidiaria con respecto al supremo mundo de la vida internalizado ya desde la socialización primaria, al igual que éste, se integran a la constitución subjetiva del individuo, no sólo como pautas de acción, sino también estableciendo estructuras de sentido, pues "constituyen realidades más o menos coherentes, caracterizadas por componentes normativos y afectivos a la vez que cognoscitivos" (p. 175). De acuerdo con esto podría decirse que la formación profesional es, en las condiciones de extremada especialización de funciones que caracteriza a las sociedades contemporáneas, una versión de gran elaboración institucional de la socialización secundaria, mediante la cual las nuevas generaciones adquieren los conocimientos específicos (Saber), así como las actitudes y valores que les permitirán desenvolverse con efectividad en la sociedad (Ser), desarrollando las funciones específicas que ésta requiere para su funcionamiento (Hacer).

Un elemento por resaltar con respecto a esta específica modalidad de interacción destinada a formar en las profesiones está referido al hecho de que se trata, casi por definición, de relaciones intergeneracionales. Los participantes 
en este tipo de interacciones; el profesor, de un lado, y los estudiantes, del otro, se encuentran, por lo común (sobre todo en el nivel de pregrado) en fases diversas de su trayecto vital, pertenecen a diferentes generaciones, en el sentido de que en razón de la extensión de su experiencia, ésta, así como su percepción del mundo y sus valores, se encuentran configurados de manera disímil; lo que Martín-Criado (2005, p. 88) señala como referente de una generación: "cambios en las situaciones de existencia que provoquen que los individuos sean generados de una manera distinta; esto es, que actúen y piensen de una manera diferente". Se tiene, entonces, que el profesor es un adulto, mientras los estudiantes, sino adolescentes, son jóvenes, lo que implica una posición existencial desde la cual, según Margulis y Urresti (1998, p. 11):

el mundo aparece nuevo, la propia historia corta, el conocimiento escaso, la memoria acumulada objetivamente menor, la vivencia de los acontecimientos diversa en relación con los que nacieron antes, todo lo cual se expresa en una decodificación diferente de la actualidad, en un modo heterogéneo de ser contemporáneo.

Este carácter intergeneracional confiere a estas relaciones un matiz especial que debe ser tenido muy en cuenta al momento de analizarlas, como se hará en lo ulterior.

Para el análisis de la interacción profesor-estudiantes, que fundamenta el proceso descrito, hemos propuesto el uso de tres categorías que, retomadas de la tradición de las ciencias sociales, pueden dar cuenta de la complejidad de estos fenómenos. Son ellas, las acciones, las concepciones y las intencionalidades. Son, insistimos, delimitaciones trazadas para fines analíticos, no facetas aprehensibles como separadas en la realidad inmediata, en la que se verifica más bien un estrecho entrelazamiento entre una y otra, ejerciéndose recíprocas influencias, retroalimentándose, orientándose unas en relación con las demás, entre otras formas en que pueden ser concebidas y por ende comprendidas las relaciones entre las tres categorías planteadas, que pasaremos a delimitar a continuación.

- Acciones: Aunque el mundo de la vida cotidiana se organiza en torno al aquí y ahora de cada individuo particular, su dinámica es interactiva, pues los componentes privilegiados de ese mundo son los otros, de manera que se trata de una realidad compartida, intersubjetiva: "no puede existir la vida cotidiana sin interactuar y comunicarse continuamente con otros. Sabiendo que los otros tienen en este mundo una perspectiva que no es idéntica a la 
mía”. (BERGER; LUCKMANN, 1968, p. 39-40). La realidad de la vida cotidiana es, pues, algo que se comparte con otros, quienes son los principales referentes y destinatarios de las acciones del sujeto. De hecho, el término 'acción', se refiere específicamente a conductas dirigidas a otros con un significado interpretable, como indicó Weber al definirla como "orientación significativamente comprensible de la propia conducta" (WEBER, 1997, p. 12). Una extensa proporción del comportamiento humano se caracteriza por estar dirigido hacia otras personas, con el fin de influir en sus respectivos comportamientos, apelando a significados socialmente compartidos; es a ello a lo que cabe llamar acción, y en este texto se referirá al aspecto evidente de la interacción de la que se presumen significados y orientaciones, como se verá adelante.

De las interacciones, es la situación "cara a cara” la de mayor importancia en tanto que prototipo del que se derivan todos los demás casos. Esta situación fundamental permite a los sujetos establecer el contacto intersubjetivo en las mismas coordenadas de tiempo y espacio y presentarse el uno al otro de la manera más inmediata posible, por lo que comparten en el mayor grado la misma realidad: "En la situación cara a cara, el otro es completamente real. Esta realidad es parte de la realidad total de la vida cotidiana." (BERGER; LUCKMANN, 1968, p. 47). Teniendo esto en cuenta se comprende la relevancia aquí otorgada a la relación profesor-estudiantes, ya que es la experiencia más real y directa que éstos tienen de la institución universitaria y profesional y el nivel mínimo sobre el cual se construye todo el andamiaje que las sustenta.

Es en este proceso de interacción, soportado en las estructuras de sentido provistas por el lenguaje, en donde el mundo social se reproduce y se transforma, en particular en el caso de las nuevas generaciones en proceso de socialización, que en virtud de éste habrán de internalizar los cúmulos de conocimiento que nutren la configuración institucional de la sociedad para así seguir actuando dentro de los principios establecidos en ésta, asegurando su perpetuación sin obviar la posibilidad de transformaciones en relación con las nuevas necesidades sociales derivadas del devenir histórico.

En este sentido, el conocimiento se halla en el corazón de la dialéctica fundamental de la sociedad: 'programa' los canales en los que la externalización produce un mundo objetivo; objetiviza este mundo a través del lenguaje y del aparato cognoscitivo basado en el lenguaje, vale decir, lo ordena en objetos que han de aprenderse como realidad. Se internaliza de nuevo como verdad objetivamente válida en el curso de la socialización. (BERGER; LUCKMANN, 1968, p. 89) 
El conocimiento se establece así como vehículo de toda vida social, que da vía a la vez que moviliza los procesos de externalización, objetivación e internalización, todos ellos, a su vez, enmarcados dentro de la densa y móvil red de interacciones que constituye el mundo humano.

- Concepciones: Es necesario resaltar que, gracias a la objetivación, los hechos naturales y sociales - dentro de los cuales hay que incluir con relieve a las otras personas - se hacen susceptibles de codificarse simbólicamente para ser apropiados y usados en las ocasiones que los actores consideren oportunas. En las situaciones de interacción tales objetivaciones tienen un doble papel. El conjunto de las objetivaciones socialmente disponibles para los interlocutores específicos constituye el marco de referencia de significados compartidos que hace posible el entendimiento de los actores, dotándolos de temas sobre los cuales desarrollar su interacción así como de criterios y esquemas de producción e interpretación de acciones comunicativas. Además, los mismos actores aparecen como objetivados ante sus interlocutores, pues son susceptibles de tipificación o inclusión en categorías amplias de clasificación de situaciones y actores, "en cuyos términos los otros son aprehendidos y tratados en encuentros 'cara a cara"' (BERGER; LUCKMANN, 1968, p. 49). Objetivaciones y tipificaciones ofrecen el sustento de significados para el mundo social cotidiano y son asumidas, reproducidas y expresadas en y desde la experiencia subjetiva como concepciones, las cuales guían la acción social del individuo.

- Intencionalidades: Pero además de dar lugar a estos procesos, la interacción se funda en una experiencia, en una particular manera de asumir el encuentro con el otro, nivel sobre el cual la fenomenología puede aportar elementos provechosos, por lo que recurriremos, para fines del estudio de la interacción en cuanto a experiencia, a la clasificación que en Verdad y Método hace H.G. Gadamer (1992) de las experiencias del tú; las modalidades que asume el encuentro del propio yo con el yo de los otros. Con ello, será posible además resaltar la tercera categoría fundamental de las interacciones educativas, el cual es puesto de relieve por la fenomenología. Se trata de la intencionalidad, como guía de la conciencia y, en este caso, de la conciencia que se tiene del otro, la cual se estudiará para cada tipo de experiencia particular.

"Existe una experiencia del tú que, observando el comportamiento de los otros hombres, detecta elementos típicos, y que gracias a esa experiencia adquiere capacidad de previsión sobre el otro" (GADAMER, 1992, p. 435). De 
tal forma traza Gadamer la primera modalidad de experiencia del tú, la cual implica, como se ve, el establecimiento de una distancia infranqueable entre el yo y el otro, desde la cual éste es encuadrado en categorías generales que permiten guiar la interacción de acuerdo a fines unilaterales, de manera que "[...] su comportamiento nos sirve como medio para nuestros fines, como lo haría cualquier otro medio." En cuanto a las implicaciones éticas de una experiencia tal, Gadamer recuerda la segunda formulación del imperativo categórico de Kant: "no se debe emplear jamás al otro como medio, sino que se le debe reconocer como fin en sí". Las interacciones educativas no están exentas de esta condición, como lo muestra el profesor cuya intencionalidad se dirige a hacer que sus estudiantes aprendan, ejerciendo sobre éstos una labor manipulativa sustentada en el supuesto conocimiento que sobre la generalidad del estudiante tiene como profesor, disolviendo la irrepetible subjetividad de cada uno en un colectivo homogéneo de aparatos cognoscitivos destinados en exclusiva a procesar la información que él tiene por trabajo entregarles. Asimismo, el estudiante que espera que su profesor le enseñe, asumiendo una actitud pasiva ante su propia formación, la que entiende como un acto mecánico que no requiere su implicación personal, es exponente de esta manera de encontrarse con el otro, reduciéndolo a los propios intereses y necesidades.

Una segunda modalidad descrita por Gadamer implica un cierto reconocimiento del otro, que no deja de ser deficiente en tanto que sigue una lógica autorreferencial, es decir, se concibe al otro como mero reflejo del yo, según una intencionalidad que pretende abarcarlo por completo y ajustarlo a la propia medida: "El uno mantiene la pretensión de conocer por sí mismo la pretensión del otro e incluso de comprenderla mejor que él mismo. Con ello el tú pierde la inmediatez con que orienta sus pretensiones hacia el otro." (GADAMER, 1992, p. 436). Se observan muestras de esta forma de relación en las aulas cuando el profesor se asume a sí mismo como pauta incontrovertible de los alumnos; como medida en relación con la cual se juzgan los actos y fines de éstos, y como único modelo de profesional y de persona inspiradora. Retomando la perspectiva intergeneracional de estas interacciones, podría leerse esta intencionalidad en términos de una concepción que M. Mead (2002) tildaría de postfigurativa, en el sentido de ese modo de transmisión cultural en la cual se reproduce lo establecido en el pasado y las nuevas generaciones aprenden dócilmente de sus mayores, estrechando de tal modo las posibilidades de innovación inherentes a las nuevas generaciones.

Existe aún un tercer tipo de experiencia en virtud de la cual es posible "[...] experimentar al tú realmente como un tú, esto es, no pasar por alto su pretensión 
y dejarse hablar por él” (GADAMER, 1992, p. 438). Se trata de una forma de relación en la que se deja al otro en libertad de manifestarse como es, en lugar de someterlo a los propios intereses o principios, ofreciendo una particular apertura, que requiere ser correspondida; es decir, este tipo de relación solo es posible cuando uno y otro están abiertos a la palabra del otro y del uno: "Si no existe esta mutua apertura tampoco hay verdadero vínculo humano" (p. 438). Se establece así una relación en verdad dialéctica, en la que los participantes entran en un contacto auténtico y transformador que requiere como precondición una intencionalidad que implique la aceptación del otro en sí mismo a pesar de las divergencias que en muchos sentidos puedan existir entre uno y otro: "La apertura hacia el otro implica, pues, el reconocimiento de que debo estar dispuesto a dejar valer en mí algo contra mí” (p. 438.). Esta sería la forma más auténtica que podría asumir la intencionalidad en la interacción educativa de las profesiones, en la que tanto el profesor como el alumno estuviesen abiertos a la palabra del otro y se dejasen transformar mutuamente. En este caso, las relaciones intergeneracionales entre profesor y alumno podrían asumir el carácter prefigurativo anunciado por Mead como el distintivo de la cultura hoy emergente en la que los jóvenes han de ser la vanguardia en la definición de las cuestiones centrales de la sociedad, estableciendo un diálogo entre generaciones

en el curso del cual los jóvenes gocen de libertad para actuar según su propia iniciativa y puedan conducir a sus mayores en dirección a lo desconocido. Entonces la vieja generación tendrá acceso al nuevo conocimiento experimental, sin el cual es imposible trazar planes significativos. (MEAD, 2002, p. 122)

La interacción entre representantes de distintas generaciones es, desde esta perspectiva, una oportunidad de mutuo enriquecimiento, pues también los jóvenes tienen algo que decir a los mayores, lo que no tiene mejor espacio para emerger que el de la formación, siempre que ésta sea concebida, en particular desde la perspectiva de los formadores, como un espacio en que tal emergencia puede tener lugar, como un proceso de mutua formación en el que no sólo los jóvenes aprenden y se desarrollan, sino que también el profesor resulta implicado en su subjetividad. Es Borrero (2006, p. 54), otra vez, quien en sus disertaciones sobre maestro y discípulo mejor ilustra esta relación:

Más que las palabras del maestro, el contacto de inteligencias en mutuo aprecio, provoca en el alma del discípulo el acto de la comprensión, la chispa de la luz intelectual que en él habita. A través de palabras y señales sensibles, las dos almas se unifican en la com- 
prensión de la verdad, que no es del maestro más que del discípulo, ni del alumno más que del maestro.

\section{Una Modalidad Especial de Interacción:}

\section{La Formación en las Profesiones}

De acuerdo con lo dicho en la sección precedente, puede concebirse la interacción formativa como un complejo que involucra la acción dirigida hacia otras personas en relación con las cuales se define, junto con las concepciones que hacen posible la comprensión entre interlocutores, y orientado según una intencionalidad, rasgo distintivo de lo pedagógico, pero que en este caso no se limita a fines funcionales de transmisión o entrenamiento, sino de genuina construcción de la subjetividad del otro.

Pero con eso aún no se ha dicho todo sobre la interacción como proceso implícito en la formación de profesionales, es necesario también considerar la dimensión subjetiva implicada en dicha interacción, que hace de ésta última un proceso continuo de construcción de identidad. A la vez que mediante la interacción cotidiana se fundamenta la realidad objetiva de las instituciones sociales, a través de ella el sujeto se construye y reconstruye continuamente al contacto con los otros. Fue G. H. Mead (1982, p. 17) quien señaló el carácter formativo de los procesos de interacción: "La interacción no es un marco simplemente para la expresión del comportamiento, sino el proceso en el que se forma el comportamiento humano." Lo que se forma mediante la interacción es la persona, concepto central en la teoría de Mead, que se opone al de organismo, en el sentido del complejo de funciones biológicas propias del hombre como perteneciente al orden natural al que puede reducirse en su estado primitivo anterior a los procesos de socialización. Al contrario, la persona constituye lo que de construcción sociocultural es el individuo humano, que, en tal sentido, ostenta un carácter de proceso en marcha. Con Mead diríamos que se está siendo humano, no que se es un ser humano: "La persona es algo que tiene desarrollo; no está presente inicialmente, en el nacimiento, sino que surge en el proceso de la experiencia y la actividad sociales” (p. 167). Además, el proceso constructivo de la persona no eclosiona de las íntimas profundidades del ser individual, antes bien, es movilizado por la continua interacción con los otros: "La persona no es algo que existe primeramente y luego entre en relación con los otros, sino que, por así decirlo, es un remolino en la corriente social y, de tal manera, una parte de la corriente” (p. 209). 
La interacción que tiene lugar entre educador y educando es una de las expresiones más claras de esta formación social de la persona, hecho que ya Borrero (2006, p. 51) hizo notar en su ensayo sobre el carácter del maestro: "Padre y madre generan el ser físico. El maestro acrecienta las herencias espirituales, intelectuales y físicas. Nadie nace del todo. El nacimiento natural es el ingreso a la vida. La educación continúa el trayecto hacia la eternidad [...]”

Desde la perspectiva hasta aquí esbozada, podrían entenderse entonces los procesos de formación profesional como interacciones institucionalmente situadas en las que mediante la internalización de los cúmulos de conocimientos de las profesiones, los estudiantes se hacen aptos para la replicación y transformación del mundo institucional de cada profesión concreta, a la vez que constituyen su identidad, su persona, como agentes de los particulares roles que dan vida a tal configuración institucional. La real relevancia de esto sólo puede apreciarse al retomar, desde esta perspectiva, la tradición más genuina de la formación como proceso de desarrollo del ser humano en tanto que tal: aquello que la cultura alemana definió bajo el nombre de 'Bildung'. Caracterizar, pues, los procesos en los que se producen las subjetividades de los profesionales requiere retomar este concepto, quizá no tanto para describir los hechos actuales como para apreciar la distancia que media entre éstos y el ideal que durante gran parte de su existencia ha nutrido la institución universitaria.

Vista la formación en términos de una específica modalidad de interacción, podría plantearse que esa especificidad viene dada por una particular configuración articulada, sobre todo, en lo que distinguiríamos como intencionalidad. En efecto, una forma de encuentro tal como la última descrita por Gadamer es legítimo fundamento de una interacción que cumpla con los más elevados fines de la función docente universitaria: la formación profesional como recreación, más que reproducción, del mundo sociocultural, a la vez que el despliegue mutuo de subjetividades, tal y como lo recoge la tradición concentrada en el vocablo alemán 'Bildung', que relaciona la educación superior con un proceso de desarrollo y refinamiento de la subjetividad, no sin ciertos ecos religiosos y con claras resonancias filosóficas. El eclipse de esta forma de concebir la función académica debido al auge de nuevos modelos que hacen gravitar en exceso esta última hacia el vértice del hacer, en completa sintonía con los imperativos del sistema económico vigente, constituye una amenaza para la esencia de la universidad y para su lugar legítimo e irrenunciable dentro de la sociedad, como verdadera formadora de los hombres y mujeres del mañana, que han de ser sujetos éticamente responsables y ciudadanos políticamente comprometidos, no sólo eficientes unidades de mano de obra calificada. 


\section{Ser, Saber, Hacer como dimensiones de la Formación en las Profesiones}

Si los procesos de interacción que mantienen y movilizan a las profesiones pueden ser designados como de formación, entonces esta formación podría ser ubicada en la intersección entre las dimensiones de la profesión y las categorías analíticas de abordaje de las interacciones. Aquellas dimensiones se integrarían además a la caracterización de la formación en las profesiones de tal modo que comprometería también ella Ser, Saber y Hacer, como guías a la vez que objetivos de la intencionalidad que ésta invoca. La asimilación que así se realiza con las dimensiones que distinguen a la profesión como hecho subjetivo e institucional se valida no sólo en la convergencia entre profesión y formación, sino en los elementos definitorios del concepto de 'Bildung', en el que se condensan muchas de las expectativas y pretensiones que definen la cultura.

- Formación para Ser: El Ser, referido a la constitución de subjetividades es quizá el rasgo eminente de la formación, debido, en parte, al discurso religioso, de fuerte acento místico, en el que se usó por vez primera el vocablo 'Bildung' para referirse a una particular experiencia propia de lo humano, pues, como informa Vierhaus (1972, p. 9) los místicos de la baja Edad Media empleaban esta voz para referirse a que el hombre estaba formado a imagen de Dios, o que el movimiento pietista planteara que gracias a la resurrección "el alma será vuelta a formar y renacerá de nuevo [...] de modo que Cristo pueda formarse en nosotros.” Con ello, ya desde sus primeros estadios, el término formación se colma de una fuerte carga humanista al señalar aquello que de divino hay en el hombre, según el pensamiento religioso medieval, lo cual será retomado y reformulado, pero no rechazado, por la filosofía moderna bajo la especie del espíritu, el cual pasará a ser el objeto privilegiado de la formación.

En la modernidad, y con el movimiento iluminista, el interés por Dios se desplaza hacia el Estado, como máxima realización de las aspiraciones del espíritu. De manera que la formación es concebida entonces como la generación de ciudadanos, guiada por el mismo Estado para asegurar su preservación. Así lo veía, por mencionar un solo ejemplo, Reseweitz, (1786) (citado por VIERHAUS, 1972, p. 13) quien recomendaba a los dirigentes de los estados europeos interesarse en la educación de sus súbditos con el fin de "infundir en su juventud los principios, templarlos en el espíritu dominante, dirigirles sus 
fuerzas vitales y corporales a toda actividad que pueda influir en la meta prevista de la constitución estatal.” Aunque quizá esta concepción pueda parecer a la sensibilidad moderna un ejemplo descarnado de ‘aparato ideológico' o de 'tecnología del poder' (de hecho, ambas categorías se han usado para realizar la crítica de las instituciones y sistemas educativos), constituye, desde otra perspectiva, un reconocimiento del potencial político-social de la formación como factor determinante para la constitución de la comunidad nacional. Esta fue una de las causas de que todo Estado moderno buscara contar con un complejo sistema educativo con pretensiones de cubrir la mayoría de la población.

Será Herder quien en la modernidad daría al concepto de formación un valor antropológico medular, al instalarlo en el centro de su sistema filosófico, convirtiéndolo en un aspecto determinante tanto del mundo natural como del género humano, el cual, a través de la historia “debe aprenderlo todo mediante una formación progresiva y dar los pasos hacia delante en una lucha permanente; se forma general o solamente allí donde tenga iguales ocasiones para la virtud, la lucha, el progreso [...]" (HERDER, 1768, citado por VIERHAUS, 1972, p. 15). Así como el universo material sigue unas pautas de desarrollo establecidas, así ocurre con el ser humano en general y con cada hombre considerado en particular, con la característica distintiva de que el desarrollo humano tiene lugar tanto en el aspecto material (corporal) como en la espiritual; a las pautas que gobiernan este proceso las llamó Herder formación. Con estos planteamientos conectaba el pensador naturaleza y cultura, materia y espíritu, pero, sobre todo, volvía a recalcar el carácter de factor distintivo de la naturaleza humana otorgado a la formación, así como la condición de proceso que ésta reviste. Si bien para Herder la formación era particular de cada individuo, no dejó por eso de reconocer, quizá más que cualquiera de sus antecesores o contemporáneos, el importante papel que la interacción juega en el proceso, al señalar al lenguaje como su medio por excelencia.

También Hegel se incluye en esta tradición, quien cimienta la formación en una condición antropológica fundamental. Lo que define al hombre es su ruptura con la inmediatez del orden natural, por lo que la naturaleza humana no está definida de antemano; él debe construirla, es decir, formarla, apartándose de la inmediatez representada en el deseo y ascendiendo a la generalidad, tanto por vía práctica, mediante la "[...] inhibición del deseo y en consecuencia libertad con respecto al objeto del mismo y libertad para su objetividad” (GADAMER, 1992, p. 41), como también por la vía teórica, consistente en "aprender a aceptar la validez de otras cosas y encontrar puntos de vista generales para aprehender la cosa, lo objetivo en su libertad, sin interés ni provecho propio.” 
La perspectiva de Hegel (1983) integra, como se ve, la formación del ser con el ejercicio teórico y la actividad práctica, según lo afirmado aquí en cuanto a la constitución de la formación profesional.

A su vez, Humboldt define la formación como "algo más elevado y más interior, el modo de percibir que procede del conocimiento y del sentimiento de toda vida espiritual y ética y que se derrama armoniosamente sobre la sensibilidad y el carácter" (citado por GADAMER, 1992, p. 39), se trata, quizá, de una de las más elocuentes definiciones de formación en tanto que cultivo de sí mismo, refinamiento de la persona en sus facultades espirituales, éticas y sensibles, que le permite percibir y actuar de manera armoniosa e intachable, lo cual será resaltado en relación con la dimensión del saber.

- Formación para el Saber: El Saber, como cultura, como conjunto de realizaciones del espíritu humano, actualizado en cada momento por cada individuo que se involucra en su formación, está también presente en las ideas que nutren la concepción moderna de formación.

El Iluminismo, en la reformulación que llevó a cabo del concepto, lo emparentó de manera estrecha, aunque no siempre convergente, con la educación. Así, para un autor de la época, von Rochow (1792, citado por VIERHAUS, 1972, p. 11)

la formación se consigue mediante la enseñanza o doctrina que media los conocimientos y forma el pensamiento [...] tarea de la escuela, por lo que a la formación de una doctrina comprensible en los seminarios (centros de formación) debe dedicarse la mayor atención. (Cursivas de Vierhaus)

Esta formulación cierra el círculo abierto por los ilustrados entre la formación de ciudadanos y la constitución de los Estados, pues la primera debe ser propiciada por éste, el cual su vez se ve fortalecido por dicho proceso. Ello es evidente en el nivel de la educación superior, cuando entre los s. XVIII y XIX, las universidades europeas, en particular en Francia, Inglaterra y Alemania, se organizan asumiendo estructuras, formas de funcionamiento y objetivos que buscaban responder a los retos planteados por la nueva organización sociopolítica del Estado-Nación. Las particularidades históricas, culturales, políticas y económicas de cada país se manifestaron en la organización de la universidad, en sus prioridades y en la forma de concebirse y concebir las finalidades del saber de la que ella era considerada gestora. La universidad alemana, por ejemplo, se 
proponía el desarrollo científico mediante la formación de investigadores que a través de su trabajo intelectual contribuyeran a la construcción de la Nación; estaba dirigida al Saber, entendido como origen y fin de toda actividad formadora. El Imperio Napoleónico concibió la universidad como formadora de los profesionales cuya acción especializada era requerida por el Estado para su funcionamiento adecuado; en ella el Saber era respaldo del Hacer. En cuanto a la universidad británica, ésta se preocupaba por la formación intelectual de los ciudadanos de manera autónoma, en el entendido de que el desarrollo del Saber sería la vía indicada para potenciar su aporte a la sociedad y a la conformación de la cultura nacional; en este caso sería el Ser el eje que articularía la acción formadora universitaria (GUTIÉRREZ, 2004)

Asimismo, para Hegel, el peregrinaje hacia la libertad es la formación, la principal dotación del ser humano. Esta formación está integrada por los productos de la cultura: el lenguaje y las costumbres; la incorporación de éstos constituye otra forma de humanización, en virtud de la cual “...el individuo se encuentra constantemente en el camino de la formación y de la superación de su naturalidad, ya que el mundo en el que ha entrado está conformado humanamente en el lenguaje y las costumbres.” (GADAMER, 1992, p. 15). Esto último llama la atención sobre el hecho de que, para Hegel, el individuo formado no queda aislado en la generalidad abstracta de la razón; al contrario, la formación le permite pertenecer con mayor plenitud y compromiso a su comunidad: insertarse en el mundo social humano, lo que ya remite al hacer en tanto que práctica.

- Formación para el Hacer: El Hacer se referiría a la dimensión práctica, de desenvolvimiento social de acuerdo con criterios éticos y morales del individuo formado, así como al componente técnico de la profesión: su apropiación de los objetos externos, que, en términos de Hegel, exigen una primera enajenación del sujeto que luego, en el momento sintético de la dialéctica así planteada, hace suyo al objeto, accediendo a su vez a una mayor generalidad.

Conviene, para no perder el rumbo de estas reflexiones, evitar la reducción del hacer al ejercicio técnico, sino ampliarlo a lo práctico, a toda acción humana a la que se le otorga un sentido y que vincula al sujeto al mundo social. En este orden de ideas resulta relevante la recuperación que lleva a cabo Gadamer de las concepciones de Helmholtz, quien incorpora a la noción de formación el componente del gusto estético, permitiendo ampliarlo hacia sus más vastas repercusiones humanas. A partir de su análisis del gusto o tacto artístico, dicho 
pensador llega a plantear que éste se relaciona con y promueve el desarrollo de una potencial facultad humana, definitiva para la vida en sociedad, "una determinada sensibilidad y capacidad de percepción de situaciones, así como para el comportamiento dentro de ellas cuando no poseemos respecto a ellas ningún saber derivado de principios generales” (GADAMER, 1992, p. 45). Muy ligado a ello está el sentido histórico, que complementa al anterior: "El que tiene sentido estético sabe separar lo bello de lo feo, la buena de la mala calidad, y el que tiene sentido histórico sabe lo que es posible y lo que no lo es en un determinado momento, y tiene sensibilidad para tomar lo que distingue el pasado del presente.” (p. 46)

Otro importante rasgo de la dimensión del Hacer de la formación es también derivado por Gadamer a partir de su estudio de diversos filósofos e intelectuales, desde Aristóteles, pasando por Vico o Baltasar Gracián. Se trata del sentido común. Más que con la doxa, la concepción de Gadamer se emparienta con la phrónesis aristotélica, esa facultad, nominada en castellano como 'prudencia', que permite comprender una situación concreta en sus implicaciones éticas y prácticas, mediante una serie de criterios de acción que no remite a la universalidad de la razón, y que versa, no sobre las cosas, sino sobre las personas y sus relaciones y estados de ánimo, permitiéndole al sujeto interactuar con los otros con tacto y consideración, sirviéndole de guía para la vida social.

Si bien lo excede, el Hacer al que alude la formación no desconoce el trabajo como modalidad privilegiada de la acción humana, mediante la cual se establece una relación con la naturaleza y entre los mismos seres humanos, organizados para llevar a cabo la actividad profesional. Sería errado asumir entonces que el ideal de la formación pretenda configurar un sujeto aislado en olímpica contemplación; antes bien, se dirige a asegurar un participante por excelencia de los procesos sociales, los que sólo con agentes provistos de calidades tales podrían ser dirigidos a lo más nobles destinos. Es Hegel, otra vez, quien confiere al trabajo el carácter de actividad característica de la existencia humana: "la formación práctica se demuestra entonces en el hecho de que se desempeña la profesión en todas las direcciones. Y esto incluye que se supere aquello que resulta extraño a la propia particularidad que uno encarna, volviéndolo completamente propio. La entrega a la generalidad de la profesión es al mismo tiempo 'un saber limitarse, esto es, hacer de la profesión una cosa propia'” (GADAMER, 1992, p. 42). Este legado sería recogido por Marx, quien continuaría, afianzándola, la incisiva crítica que Hegel había enfrentado a las formas que asumía tan importante actividad en el mundo moderno. Ambos juzgaban que la forma en que el trabajo se efectuaba en la sociedad moderna iba en contra 
de su propia naturaleza y terminaba por ser medio de la alienación humana, en lugar de vía para su liberación y su plenitud: "este trabajo, que tiende hacia el objeto como un todo, se distribuye en sí mismo y se convierte en un trabajar individual y este trabajar individual llega a ser precisamente más mecánico porque de él queda excluida la multiplicidad, convirtiéndose por tanto este trabajar, por sí mismo, en algo más general, más ajeno a la totalidad" (HEGEL, 1983, p. 127). En los términos aquí expuestos la alienación con respecto al trabajo puede ser planteada como disgregación entre el Ser, el Saber y Hacer, que convierte al hombre en mudo instrumento del aparato productivo, quedándole como única posibilidad el refugiarse en una acorazada intimidad por completo incapaz de actuar sobre el mundo objetivo. Es, pues, la distorsión del trabajo lo que atenta contra la realización de la humanidad, no aquello que es el trabajo en su esencia, como recuerda K. Jaspers al calificarlo como "comportamiento fundamental del ser humano", por medio del cual se humaniza tanto el propio hombre como la naturaleza, dando origen así al mundo humano (citado por FERRATER, 2004, p. 35-51).

Podemos recuperar de lo dicho hasta aquí sobre el concepto de formación, que éste, desde la tradición de la Bildung, se refiere, antes que nada, a un rasgo distintivo de la condición humana, a su carácter inacabado, de proyecto o proceso, de potencia que exige ser actualizada. Esa actualización se logra, de manera privilegiada, a través de un proceso intelectual y práctico que implica a la educación como relación con el legado espiritual de la humanidad, el cual, siendo apropiado por el individuo, lo forma. La educación vincula a los individuos a través del lenguaje, vehículo de la tradición acumulada que, incorporada por cada uno, permite su integración a la sociedad y lo habilita para la potencial innovación y transformación de ésta, siendo esta finalidad social otro aspecto distintivo de la formación que se entiende entonces como fundamento de las colectividades políticas que son los estados nacionales. En el marco de la vida en sociedad la formación implica dos aspectos relevantes: el sentido estético e histórico y la prudencia, ligados a la sensibilidad y el refinamiento espiritual logrados por el proceso antecedente: sentido estético e histórico que permiten en conjunto el juicio de situaciones diversas de la vida social de acuerdo con los más amplios criterios; prudencia que guía la acción del sujeto según imperativos éticos.

Ya hemos advertido respecto del carácter ideal de esta concepción que si bien ofrece posibilidades de comprensión de hechos empíricos, lo hace en tanto que patrón con respecto al cual medir la distancia entre lo que en efecto son en la actualidad nuestros procesos educativos universitarios y lo que 
quisiéramos que tales procesos fueran, al reconocer la tradición que en esta institución pervive, en cuanto a la manera de llevarse a cabo, a sus fines y a sus resultados en términos de constitución de la subjetividad de los estudiantes. El reconocer la tradición de la Bildung y a la universidad como una de sus principales portadoras, y que como tal debería promoverla, al tiempo que se señala la interacción cotidiana como fundamento de tal institución, exhorta a formular una serie de preguntas sobre nuestra situación actual con respecto a los procesos de formación profesional.

\section{Una Propuesta Metodológica para el Estudio de las Interacciones Formativas en las Profesiones}

¿Cómo se integran, en la enseñanza universitaria, las dimensiones profesionales del Ser, el Saber y el Hacer? ¿Son ellas pautas para el desarrollo del proceso educativo en cada profesión específica? ¿Reconocen los actores tales dimensiones como constitutivas de la formación profesional en la que se desenvuelven? ¿Conciben en especial la dimensión del Ser como dimensión distintiva de la profesión y de la formación que a ella tiende? ¿Cómo se desarrollan tales dimensiones en la cotidianidad de los procesos formativos institucionalmente situados? ¿Son éstos procesos de tipo instrumental o de hecho implican el genuino encuentro de subjetividades? ¿Qué intencionalidades los movilizan? ¿Cuáles son las acciones que caracterizan las relaciones entre profesores y estudiantes? ¿Qué concepciones mantienen unos sobre otros y sobre los factores relevantes que determinan la interacción? Si las interacciones conforman el tejido que fundamenta toda institución, ¿qué carácter asumen la universidad y la profesión a partir de estas interacciones entre sus actores? ¿La formación, como tiene lugar en las universidades de hoy, propicia el desarrollo integrado de las dimensiones que la caracterizan? ¿Cómo se articulan las dimensiones que configuran la profesión, en la dinámica de la formación? ¿Se corresponde la formación profesional desarrollada en las universidades con los requerimientos más sensibles de la sociedad en la que éstas se insertan?

Motivada por preguntas como las anteriores, y a lo largo de años de indagación, se ha venido madurando la reflexión sobre la teoría y la práctica pedagógica en la educación superior, reflexión que en cierto punto exigió contraste empírico, para lo cual, siguiendo senderos conceptuales similares a los aquí trazados, se generaron metodologías e instrumentos específicos implementados en la realización de una serie de estudios de caso sobre las interacciones profe- 
sor-estudiantes en programas académicos ofrecidos por distintas instituciones de educación superior² .

A la vez que han movilizado la reflexión teórica, las investigaciones realizadas han permitido el planteamiento y posterior ajuste de una propuesta metodológica para el análisis e interpretación de las interacciones profesorestudiantes en el marco de la educación superior. Las categorías que componen dicha propuesta se desprenden de las consideraciones conceptuales precedentes en lo relativo a la caracterización de las profesiones como formaciones institucionales que tipifican de manera flexible Ser, Saber y Hacer, que a su vez constituyen las dimensiones componentes de todo proceso formativo profesional. En relación con ello se toma el fenómeno de la interacción, analizándolo según las tres categorías ya señaladas: concepciones, intencionalidades y acciones. Entre estas categorías y las dimensiones propias de la formación -Ser, Saber y Hacer-, se establecen interrelaciones que permiten organizar las interacciones formativas profesionales a partir de los discursos de los actores: estudiantes y profesores. Para aprehender en su complejidad la situación interactiva a partir de los discursos de uno y otro actor, el enfoque tiene en cuenta no sólo la expresión de cada actor sobre sus propias concepciones, intencionalidades y acciones, sino también aquellas relativas a las concepciones, intencionalidades y acciones de la contraparte, permitiendo así abordar no sólo lo que estudiantes o profesores, creen, pretenden o hacen, sino también lo que uno y otro supone, percibe o interpreta de lo que el otro cree, pretende o hace, recuperando de tal forma el carácter interactivo de la situación cara a cara. De acuerdo con lo anterior, se construyó una matriz en la que es posible organizar los discursos teniendo en cuenta actores (profesor y estudiantes), dimensiones de la profesión (ser, saber y hacer) y categorías de la interacción (concepciones, intencionalidades y acciones), todo ello en relación con los más destacados aspectos de la formación universitaria: la institución, la identidad profesional, las características del programa formativo específico, el perfil esperado del egresado, la condición de estudiante, el papel del docente, el proceso de enseñanza-aprendizaje.

Cabe mencionar la posibilidad teórica de una tercera perspectiva, complementaria de las dos primeras que se acaban de mencionar. Así como puedo

2 El estudio se apoyó en la línea de investigación sobre Procesos formativos en educación superior de la Maestría en Educación de la Pontificia universidad Javeriana. Con estudiantes de la maestría, bajo la dirección de la autora, se desarrollaron, como trabajos de grado, estudios de caso sobre las interacciones en el ámbito de programas como: Ingeniería electrónica, Psicología Empresarial, Contaduría, Licenciatura en Electrónica, Licenciatura en Química, Antropología, Enfermería, Odontología, Bacteriología, Microbiología industrial y Seminario de formación sacerdotal. En conjunto, el desarrollo de los estudios abarcó un periodo de ocho años e implicó a una variada muestra de instituciones de educación superior de la ciudad de Bogotá. 
dar cuenta, en el discurso, de mis propias acciones, concepciones e intencionalidades, y también de aquellas acciones, concepciones e intencionalidades que percibo, intuyo o interpreto de los otros, es posible además que tome en consideración, manifestándolo, lo que supongo con respecto a lo que el otro puede a su vez suponer sobre mis propias acciones, concepciones e intencionalidades. Se trata de un sendero que apenas empieza a explorarse en esta línea de investigación.

Esta manera de abordar el fenómeno de nuestro interés determinó la construcción de una matriz, instrumento específico para la categorización, de acuerdo con los ejes conceptuales ya indicados, de los discursos de estudiantes y profesores que fueron producidos mediante entrevistas semiestructuradas dirigidas, en primera instancia, a la reconstrucción de la vida cotidiana del aula de clase con énfasis en las interacciones entre profesores y estudiantes. La opción por este modo de producción de datos en lugar de la observación directa responde a la perspectiva adoptada con respecto a la interacción, desde la cual se hace especial énfasis en la faceta subjetiva de la experiencia cara a cara, en la vivencia particular de los actores que se hace evidente, así sea a través de indicios, al valerse del instrumento que la hace posible: el lenguaje, más que desde la mera objetividad que registra la observación externa.

La matriz fue entonces un instrumento de análisis, cuyo producto sirvió de insumo para el proceso de interpretación y reconstrucción de las interacciones formativas profesionales propias de los programas universitarios estudiados, pero también ella fue objeto de ajustes conforme era implementada en cada uno de los proyectos particulares. Así, en este punto, el instrumento ha llegado a un estado de refinamiento que consideramos adecuado como para ser sometido al arbitrio de la comunidad científica, para lo cual, además de mostrarla en el anexo correspondiente, se ilustrará su estructura analítica extrayendo algunas muestras de fragmentos discursivos definidos mediante su uso.

La forma en que los actores entienden los principales referentes que definen el horizonte de la interacción se rescata en la sección de Concepciones, en la que se ubican declaraciones como la siguiente, en la que un profesor de la carrera de Ingeniería Electrónica explicita la manera en que la profesión que ejerce y enseña configura su identidad:

Más que desarrollar una profesión se volvió un estilo de vida, porque ciertas carreras te exigen ciertas cosas de tu vida, de tu vida profunda $y$ de tu vida profesional [...] en ciertos aspectos le define un derrotero muy estricto, [...] le gusta u na vida como bastante cuadriculada, bastante rigurosa [...] se vuelve cuadriculada desde el punto de vista 
que siempre se tratan de buscar mecanismos y métodos 'exactos' para buscar una meta.

La manifestación de una concepción propia sobre un tema como la identidad profesional, relativo, según nuestra caracterización, a la dimensión formativoprofesional del Ser, ubica esta declaración en la intersección de dicha dimensión con la categoría de 'Concepciones'. También son coordenadas del citado ejemplo el rótulo 'Profesor', y la subcategoría inclusa en éste 'Se expresa a sí mismo' (abreviada a 'Sí mismo'). El primero indica al sujeto que emite el discurso, mientras que la mencionada subcategoría apunta al hecho de que este sujeto hace referencia a su propia subjetividad en el discurso.

En la interacción, como aquí se ha formulado, reviste importancia capital lo que cada actor interprete de la acción del otro, creándose de tal modo un referente, más o menos cercano a la subjetividad de éste, sobre sus concepciones, intencionalidades y acciones; de allí la inclusión, dentro del rótulo que identifica a cada clase de actor, profesor o estudiante, de la subcategoría 'Expresa lo que interpreta del otro' (abreviada a 'Otro'). Con ello, se puede acceder a la manera en que cada uno construye la relación desde su particular posición en la institución; así por ejemplo, en el caso de las concepciones, un estudiante de Ingeniería Electrónica afirmó que hacia los semestres finales de la carrera, los profesores:

ya lo ven [al estudiante] como un ingeniero, entonces ya creo que hay un poco más de amistad o digámoslo así de cercanía, entre profesor y alumno.

De manera implícita, el estudiante deja emerger uno de los factores de distanciamiento que interponen los profesores respecto a los alumnos y que se atenúa en la fase final de la carrera.

También se interpretan las intencionalidades del interlocutor, como muestra el joven en formación sacerdotal en relación con sus maestros, quienes, según él:

Se preocupan por cuestionar a sus estudiantes de manera tal que para ellos la comprensión de los asuntos sea clara y cada día se convenzan más de su elección profesional (Estudiante, Otro-IntencionalidadesSer-Referente: carrera).

De paso, este ejemplo nos permite mostrar cómo contrastar y otorgar valores de significación a los datos analizados según esta propuesta, lo que es posible 
mediante la comparación de discursos ubicados en similares coordenadas en cuanto a los ejes Interacción y Formación Profesional, pero emitidos por diferentes actores. En el caso del Seminario de formación sacerdotal, por ejemplo, se puede comparar la intencionalidad interpretada por el estudiante mostrada en el ejemplo anterior, con la expresión de la propia intencionalidad generada por uno de sus profesores:

desde la confrontación el estudiante ha de ir descubriendo estrategias de aplicación, que adecúe su pensar y su quehacer, y que involucre este quehacer en el proceso de adquisición del conocimiento (Profesor-Sí mismo-Intencionalidad-Hacer-Referente: Enseñanzaaprendizaje).

Con ello, en este caso, parece resultar muy consistente el elemento de confrontación o cuestionamiento como característico de las interacciones formativas propias de esta formación, lo que se reafirma con esta otra declaración de uno de los profesores, en este caso relativa a las acciones:

creo que lo primero que se hace dentro del proceso para llegar a una situación propositiva, es tratar de poner en tensión fuertemente las estructuras que trae [el estudiante] y los conocimientos previos que posee, y ponerlos en tensión es de alguna forma que él empiece a modificarlos (Profesor-Sí mismo-Acción-Saber-Referente: enseñanza-aprendizaje).

Según lo afirmado a lo largo de esta exposición, en el propio desenvolverse de las interacciones se hace manifiesto el entramado institucional que las estructura y a cuya perpetuación - como también eventual transformación - ellas contribuyen: la lógica de la profesión, pero también las particularidades distintivas de cada programa académico y cada universidad. De manera que, así como la formación sacerdotal por su propia naturaleza requiere de la confrontación como estrategia pedagógica por excelencia para el trabajo de radical reconstrucción de la identidad del sujeto que implica esta profesión, otras profesiones serán más inclinadas a otro tipo de estrategias pedagógicas y didácticas. Así, por ejemplo, en la ingeniería parece prevalecer una concepción del proceso educativo con fuerte acento instrumental, en el cual el estudiante es relegado a un papel bastante pasivo, como parece entenderlo el profesor que expresó que:

[el estudiante] viene aquí a la universidad a que lo formemos desde el punto de vista de la tecnología, a que lo formemos desde el punto 
de vista de la personalidad, desde el punto de vista de lo ético” (Profesor-Otro-Intencionalidad-Ser-Referente: estudiante).

Tal visión unidireccional de la relación educativa se corresponde con una perspectiva similar del proceso de aprendizaje, en el cual el estudiante sería poco más que una tabula rasa:

en la parte del estudiante el aprendizaje yo lo veo como una parte en la que él recibe conocimiento, lo que tú le estás enseñando" (Profesor, Sí mismo-Concepción-Saber-Referente: estudiante).

Otro tanto ocurre con la carrera de Contaduría, la cual, al ser definida en términos de estricta vigilancia legal, es apropiada, reinterpretada y objetivada de continuo por sus propios portadores profesionales, incluyendo estudiantes, como un ámbito configurado por normatividades de diversa índole, cuya lógica, concentrada en los criterios de corrección formal y de vigilancia y control, llega a hacerse parte de la vivencia misma de los profesionales y estudiantes. Todo lo dicho parece condensarse en la siguiente declaración de uno de los profesores de esta carrera:

Yo siempre les inculco a ellos responsabilidad como una norma porque la ley lo exige, entonces no existiría sino solamente la ética, pues la ética es moral, pero además de la ética existe un ente que lo exige en una norma que exige que una declaración de renta tiene que ir firmada por un Contador" (Profesor: Sí mismo-ConcepciónHacer-Referente: profesión).

Tras afirmaciones como las anteriores y más aún en otra como ésta:

el interés de muchos docentes es más hacia dictar su clase y punto, va a su clase la dicta, se acabó y punto” (Estudiante: Otro-Intencionalidad-Hacer-Referente: enseñanza-aprendizaje).

Que para mayor ironía se refiere a un programa de licenciatura, pareciera insinuarse el imperio de una orientación instrumental de la interacción, de acuerdo con una intencionalidad similar a la primera de las descritas por Gadamer. Sin duda es una realidad de nuestras instituciones educativas, también ellas sometidas a los principios de racionalidad instrumental y máximo rendimiento tan poco propicios al desarrollo de una genuina cultura de la formación del sujeto. No obstante, algo de la tradición propia de la institución universitaria pervive y se hace manifiesta en declaraciones de estudiantes y profesores que conciben el acto educativo como auténtico encuentro de subjetividades que se 
reconocen una a la otra, así, por ejemplo, y para mostrar que estos contrastes tienen lugar hasta en los mismos programas, la declaración de otro profesor de Licenciatura en Química:

los alumnos y las alumnas no son personas pasivas objeto de trabajo sino personas que tienen mucho que aprender pero también mucho que enseñar (Profesor: Sí mismo-Concepciones-Ser- referente: estudiantes).

En uno de los programa de licenciatura es, de hecho, donde se expresa muy claramente la intencionalidad propiamente formativa, lo que puede responder, en parte, a su componente pedagógico, pero también ser una forma de resolver las acentuadas tensiones de las que es objeto esta carrera, como la mayoría de las licenciaturas relacionadas con las ciencias naturales, percibidas incluso por sus mismos estudiantes y profesores como inferiores en relación con las disciplinas puras o con las ingenierías, lo que tratan de compensar exaltando la importancia humana y social de la labor educativa, como se hace palpable en lo dicho por un estudiante de Licenciatura en Electrónica:

Puedo ser un buen ingeniero, me puedo ir a trabajar, ganar platica, pero ¿realmente está haciendo algo por contribuir?, de pronto a la economía del país, pero no en algo más directo. La licenciatura me parece algo más directo cuando uno llega y se para frente, aunque sea diez muchachos y no sólo se dedica a dar una clase de circuitos, sino también a dar una clase de sociedad, de cultura. A veces a los profesores se les escapa una palabra, y esa palabra influye mucho en el alumno; entonces, realmente estoy haciendo un aporte para el país, sobre diez cabezas, y esto va a ser algo realmente grande, no estoy pasando en blanco mi vida, haciendo plata para mí, sino que puedo hacer algo; además, la licenciatura no da mucha plata $^{3}$ (Estudiante: Sí mismo-Intencionalidad-Hacer-Referente: profesión).

Volviendo a la Licenciatura en Química, encontramos en los discursos, sobre todo de los profesores, pero también de alumnos, interesantes reflexiones y pautas de intención y acción hacia el ejercicio educativo, como por ejemplo

3 Aunque no es este el lugar para abundar sobre este caso específico, no podemos evitar decir que esta contradicción, arraigada en el bajo reconocimiento social y en las estrechas expectativas económicas que aquejan a la generalidad de las Licenciaturas, genera profundas fisuras en la identidad profesional, tanto de licenciados como de estudiantes, que, por lo general, juzgan su propia carrera como paso obligado para lograr otro tipo de proyectos. En un marco tal, una genuina formación difícilmente prospera, por más elaborados que sean los discursos pedagógicos que la alimenten, pues, como se ha insistido aquí, como fenómeno social, la formación está en estrecha vinculación con el entramado institucional y de interacción en el que tiene lugar. 
aquel profesor que menciona, al describir la categoría de acción de su propia práctica formativa:

La construcción de un ambiente favorable yo lo planteo en un comienzo en una construcción colectiva de todos [...] Es un punto grandísimo cuando empezamos a mirar, a concertar planes de trabajo, [...] cuando eso yo lo dejo a un lado cuando yo dejo del problema de lo que en los códigos que ahí, en el dogma que hay que dar a los estudiantes frente a las relaciones contractuales, cuando yo dejo eso de un lado y empiezo a charlar, hay unos espacios y sobre esos podemos generar unas temáticas propuestas que modificamos (Profesor: Sí mismo-Acción-Saber-Referente: enseñanza-aprendizaje).

Es significativo que uno de los obstáculos a superar para lograr esta relación de reciprocidad entre profesor y estudiantes, se refiera al mismo aparato institucional, que así, en vez de favorecer, estaría entorpeciendo el encuentro entre sus cotidianos constructores, que por cierto, además del enriquecimiento humano que comporta, resulta fructífero como estrategia didáctica, según se entiende de lo dicho por una estudiante del mismo programa:

entonces ellos llegan y dicen tenemos que respetar a los demás respetarles la palabra y que esa persona si me puede respetar algo a mí, y que en la medida en que yo escuche a los demás puedo aprender muchísimo más, que inclusive yo empezando a leer de manera personal, o sea que ese escuchar, me enriquece más (Estudiante: Sí mismo-Intencionalidad-Saber-Referente: enseñanza-aprendizaje).

Las breves viñetas mostradas hasta aquí no pretenden otra cosa que ilustrar la puesta en práctica de una estrategia concebida con el propósito explícito de acceder a la comprensión de las interacciones formativas en las profesiones como núcleo de la institución universitaria. Como puede apreciarse, permite llevar a cabo, en primera instancia, la fase analítica de los discursos por medio de los cuales los actores representan sus interacciones, para luego permitir una reconstrucción interpretativa de éstas, en diálogo con los entornos institucionales más amplios en los que se inserta su sentido. De este modo pueden caracterizarse desde los mismos actores específicos de una situación interactiva de formación profesional, tanto el nivel medio que constituye el programa académico en cuestión, como la institución al que este pertenece. En última instancia, pueden ofrecerse algunos elementos que den cuenta de la situación de la profesión en determinado momento y lugar, gracias a la caracterización previa de sujetos y de regiones específicas del campo. Aunque erigida sobre las bases teóricas de 
una sociología que podría llamarse "construccionista" o "fenomenológica" y de acuerdo con una visión que reconocemos es muy específica del concepto de formación, en principio esta propuesta no entraría en contradicción con su apropiación por de diversas corrientes teóricas que tiendan a acentuar uno $u$ otro de sus elementos específicos.

\section{Conclusión}

Los momentos de crisis tienen la facultad de llevarnos a considerar aquello que nos es más propio, de lo que de ninguna manera podríamos prescindir y que en medio de la turbulencia puede ayudarnos a encontrar un norte a pesar de todo. No es exagerado calificar de crítica la situación actual de la universidad, sobre todo en lo que a formación profesional importa, de manera que también en este caso es imprescindible identificar y propiciar un fundamento sólido para asegurar la misma pervivencia y ulterior desarrollo de la institución en los tiempos inciertos en los que nos internamos.

La propuesta aquí formulada, de encontrar dicho fundamento en la interacción formativa, recuperando arraigadas tradiciones y actualizándolas, trata, entonces, de consolidar hacia el futuro ese papel propio de la universidad, a un tiempo conservador y transformador de su entorno social. El acaparamiento - por intermedio de la tecnología y el sistema económico - del conocimiento para excluyentes fines de rentabilidad, comporta como una de sus más lesivas implicaciones la sumisión del conocimiento a las leyes propias de la producción y el consumo, lo que se manifiesta, entre otras maneras, en el funcionalismo tecnocrático imperante en los procesos educativos contemporáneos, sobre todo en el nivel superior. A ello, que mutila la riqueza espiritual producida por la auténtica formación, es perentorio oponer una concepción humana de la educación, que mantenga vivo ese carácter de acción distintiva de nuestra especie y de vía regia para el despliegue de todas las posibilidades - no sólo las productivo-económicas - que son propias de la condición humana.

Lo anterior sólo puede ser eficaz si se moviliza desde la reflexión rigurosa y la investigación exhaustiva, que demuestren que lo racionalmente admisible es también lo éticamente válido. A ello responde el hecho de haber complementado nuestra recuperación de elementos teóricos con la presentación de un producto metodológico derivado de estudios empíricos, que juzgamos, hace posible hallar referentes objetivos para la discusión planteada en el plano teórico, a la vez que permite apropiar los conceptos en discusión como referentes para la organización de la realidad estudiada. 
Pero, además de ello, la propuesta metodológica aquí presentada ofrece inmediatos dividendos para la labor educativa en el nivel superior. En primer lugar, porque a la vez de señalar su relevancia, ofrece los elementos básicos para la construcción curricular congruente, es decir, con general correspondencia respecto al programa de que se trate, a la vez que pertinente, en relación con los requerimientos sociales relevantes desde la perspectiva de la profesión correspondiente. Al permitir señalar los componentes de cada profesión específica, desde el plano más individual y subjetivo, hasta los complejos entramados institucionales, pasando por la estructura simbólica que es su patrimonio distintivo, la propuesta indicada permite que tales componentes se integren y sirvan como guías del proceso de diseño curricular, que, de tal modo, se articulará tanto con las expectativas subjetivas de estudiantes, profesores y profesionales en general, como con las demandas sociales del momento, sin desvirtuar por ello lo que distingue a la profesión específica.

Otro aspecto de relevancia tiene que ver con la posibilidad de una genuina formación por competencias, en tanto que los términos de la formación aquí acogidos configuran una visión del sujeto y de su actividad profesional que integra de manera unitaria el carácter multidimensional de ambos, lo que ha tratado, con desigual acierto, de ser puesto en escena por el término 'competencia'. Ser, Saber, Hacer son, pues, también dimensiones cuya sinergia constituye el fundamento de la actuación competente. Una formación orientada a estas dimensiones no sería otra cosa que verdadera formación por competencias.

\title{
Referencias
}

\begin{abstract}
ARIAS, J.; PALLARES, J.; REYES, A. Caracterización de las interacciones estudiante-profesor en los procesos formativos de la educación superior: estudio de caso, carrera de microbiología industrial. 2005. Tesis (Maestría en Educación) - Pontificia Universidad Javeriana, Bogotá, 2005.
\end{abstract}

BALLESTEROS, F.; MONTOYA, C.; MORALES, C.; RANGEL, E. Interacciones profesor-estudiante en la educación superior: el caso del seminario intermisional diocesano. 2002. Tesis (Maestría en Educación) - Pontificia Universidad Javeriana, Bogotá, 2002.

BERGER, P.; LUCKMANN, T. La construcción social de la realidad. Buenos Aires: Amorrortu, 1968. 
BORRERO, A. Conferencia II: Idea de la universidad en sus orígenes. En: SIMPOSIO PERMANENTE SOBRE LA UNIVERSIDAD, Bogotá, 2006.

BORRERO, A. Conferencia VI: Educación en lo superior y para lo superior. En: SIMPOSIO PERMANENTE SOBRE LA UNIVERSIDAD, Bogotá, 2006.

BORRERO, A. Conferencia XXXIV: Títulos y profesiones. En: SIMPOSIO PERMANENTE SOBRE LA UNIVERSIDAD, Bogotá, 2006.

BOURDIEU, P. El oficio de científico: ciencia de la ciencia y reflexividad. Barcelona: Anagrama, 2003.

BULLA, J.; GIRALDO, J.; MANRIQUE, M.; MARROQUÍN, J. Interacciones profesor-estudiante en la carrera de ingeniería industrial en la Pontificia Universidad Javeriana. 2002. Tesis (Maestría en Educación) - Pontificia Universidad Javeriana, Bogotá, 2002.

CASTELLANO, F.; GARAVITO, A. Las interacciones estudiante-profesor en los procesos formativos de la educación superior: el caso de la Facultad de Enfermería de la Pontificia Universidad Javeriana. 2001. Tesis (Maestría en Educación) - Pontificia Universidad Javeriana, Bogotá, 2001.

CASTELLS, M. La sociedad red: una visión global. Madrid: Alianza Editorial, 2006.

DÍAZ, V.; GUARÍN, A. Caracterización de las interacciones estudianteprofesor en los procesos de formación en la educación superior: el caso de Ingeniería Electrónica en la Universidad Santo Tomás y la Licenciatura en Electrónica en la Universidad Pedagógica Nacional. 2003. Tesis (Maestría en Educación) - Pontificia Universidad Javeriana, Bogotá, 2003.

ESCOBAR, F. Las Interacciones profesor-estudiantes en los procesos formativos del programa de odontología de la Pontificia Universidad Javeriana. 2004. Tesis (Maestría en Educación) - Pontificia Universidad Javeriana, Bogotá, 2004.

ESTUPIÑÁN, G.; GARZÓN, C. Interacciones estudiante-maestro en los procesos interactivos de la educación superior: caso Facultad de Contaduría, Jornada Diurna, Universidad Antonio Nariño. 2001. Tesis (Maestría en Educación) - Pontificia Universidad Javeriana, Bogotá, 2001.

FERRATER, J. Trabajo. En: Diccionario de Filosofía. Barcelona: Ariel, 2004. T. 4 (Q-Z), p. 35-51. 
GADAMER, H.-G. Verdad y método. Salamanca: Sígueme, 1992.

GARDNER, H.; CSIKSZENTMIHALYI. M.; DAMON, W. Buen trabajo: cuando ética y excelencia convergen. Barcelona: Paidós, 2002. (Obra original en inglés: GoodWork: When excellence and ethics meet, publicada en 2001).

GARDNER, H.; FISCHMAN, W.; SOLOMON, B.; GREENSPAN, D. Making good: how young people cope with moral dilemmas at work. Cambridge, MA/London, UK: Harvard University Press, 2004.

GOLDSTEIN, T. Los albores de la ciencia. De los árabes a Leonardo da Vinci. México: Fondo Editorial Interamericano, 1984.

GUTIÉRREZ, C. La construcción de identidad: Sentido de la universidad. Tendencias y retos, Bogotá, n. 9, p. 103-117, 2004.

HEGEL, G. W. F. El sistema de la eticidad. Madrid: Nacional, 1983.

MEAD, G.-H. Espíritu, persona y sociedad. Buenos Aires: Paidós, 1982.

MEAD, M. Cultura y compromiso. Barcelona: Gedisa, 2002.

MARGULIS, M.; URRESTI, M. La construcción social de la condición de juventud. En: CUBIDES, H.; LAVERDE, M.; VALDERRAMA, C. Viviendo a toda: jóvenes, territorios culturales y nuevas sensibilidades. Bogotá: Universidad Central-Siglo del Hombre, 1998.

MARTÍN-CRIADO, E. La construcción de los problemas juveniles. Nómadas, Bogotá, n. 23, 2005.

MORA, A.; RODRÍGUEZ, E.; SANTANA, G.; VALDÉS, E. Las interacciones profesor-estudiante en los procesos formativos del Programa de Psicología Empresarial de la Universidad Piloto de Colombia. Bogotá: [s. n.], 2004.

PERALTA, F.; VELA, P. El juego de las interacciones en la construcción de identidad del licenciado en química. Bogotá: [s. n.], 2001.

SCHALER, J. A. Howard Gardner under fire: the rebel psychologist faces his critics. Chicago/La Salle, IL: Open Court, 2006.

URIBE, M.; PATIÑO, M.; NÚÑEZ, Y.; DORADO, P. Las Interacciones profesor-estudiante en los procesos formativos de la educación superior: El caso de Antropología en la Universidad de los Andes. Bogotá: [s. n.], 2002. 
VASCO, C. E. The second Gardner's late shift: From psychology to outer space? En: SCHALER, J. A. (Ed.), Howard Gardner under fire: the rebel psychologist faces his critics. Chicago/La Salle, IL: Open Court, 2006. p. 203-215.

VIERHAUS, R. Formación. Separata de la Revista Educación y Pedagogía, v. 2, n. 14, 1972.

WEBER, M. Economia y sociedad: Esbozo de sociología comprensiva. México: FCE. 1995. 
MATRIZ PARA EL ANÁLISIS DEL DISCURSO DE LOS A

\begin{tabular}{|c|c|c|c|c|c|c|}
\hline \multirow{2}{*}{\multicolumn{2}{|c|}{$\begin{array}{r}\text { FORMACION } \\
\text { PROFESIONAL }\end{array}$}} & \multicolumn{4}{|c|}{ SER } & \\
\hline & & \multicolumn{2}{|c|}{ Profesor } & \multicolumn{2}{|c|}{ Estudiante } & \\
\hline \multicolumn{2}{|l|}{ INTERACCIÓN } & $\begin{array}{l}\text { Se expresa a sí } \\
\text { mismo }\end{array}$ & $\begin{array}{l}\text { Expresa lo que } \\
\text { interpreta del } \\
\text { estudiante }\end{array}$ & $\begin{array}{l}\text { Se expresa } \\
\text { a sí mismo }\end{array}$ & $\begin{array}{l}\text { Expresa lo } \\
\text { que inter- } \\
\text { preta del } \\
\text { profesor }\end{array}$ & $\begin{array}{l}\text { Se expresa a sí } \\
\text { mismo }\end{array}$ \\
\hline REFERENTES & \multirow[b]{2}{*}{ 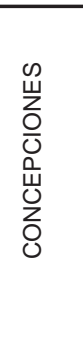 } & \multirow{2}{*}{$\begin{array}{l}\text { Dice que el refer- } \\
\text { ente ES, debe } \\
\text { SER, o debe } \\
\text { aportar a la for- } \\
\text { mación del SER. }\end{array}$} & \multirow[b]{2}{*}{$\begin{array}{l}\text { Dice que el estu- } \\
\text { diante cree sobre } \\
\text { lo que el referente } \\
\text { ES, debe SER, } \\
\text { o debe aportar a } \\
\text { la formación del } \\
\text { SER. }\end{array}$} & \multirow{2}{*}{$\begin{array}{l}\text { Dice que el } \\
\text { referente ES, } \\
\text { debe SER o } \\
\text { debe apor- } \\
\text { tar a la for- } \\
\text { mación del } \\
\text { SER. }\end{array}$} & \multirow[b]{2}{*}{$\begin{array}{l}\text { Dice que el } \\
\text { profesor cree } \\
\text { sobre lo que } \\
\text { el referente } \\
\text { ES, debe } \\
\text { SER o debe } \\
\text { aportar a la } \\
\text { formación } \\
\text { del SER. }\end{array}$} & \multirow{2}{*}{$\begin{array}{l}\text { Dice que el refer- } \\
\text { ente SABE, debe } \\
\text { SABER o debe } \\
\text { aportar a la for- } \\
\text { mación del SA- } \\
\text { BER. }\end{array}$} \\
\hline \multirow{2}{*}{$\begin{array}{l}\text { Universidad } \\
\text { Profesión } \\
\text { Carrera } \\
\text { Perfil del } \\
\text { Egresado } \\
\text { Estudiante } \\
\text { Docente } \\
\text { Enseñanza- } \\
\text { aprendizaje } \\
\text { Formación. }\end{array}$} & & & & & & \\
\hline & 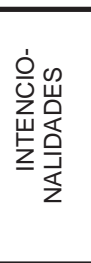 & $\begin{array}{l}\text { Lo que dice que } \\
\text { guía su acción } \\
\text { hacia la for- } \\
\text { mación del SER } \\
\text { en relación con } \\
\text { el referente. }\end{array}$ & $\begin{array}{l}\text { Lo que dice que } \\
\text { guía la acción del } \\
\text { estudiante hacia } \\
\text { la formación del } \\
\text { SER en relación } \\
\text { con el referente. }\end{array}$ & $\begin{array}{l}\text { Lo que dice } \\
\text { que guía su } \\
\text { acción hacia } \\
\text { la formación } \\
\text { del SER en } \\
\text { relación con } \\
\text { el referente. }\end{array}$ & $\begin{array}{l}\text { Lo que dice } \\
\text { que guía la } \\
\text { acción del } \\
\text { p rof e s or } \\
\text { hacia la for- } \\
\text { mación del } \\
\text { SER en rel- } \\
\text { ación con el } \\
\text { referente. }\end{array}$ & $\begin{array}{l}\text { Lo que dice que } \\
\text { guía su acción ha- } \\
\text { cia la formación } \\
\text { en el SABER en } \\
\text { relación con el } \\
\text { referente. }\end{array}$ \\
\hline \multirow{3}{*}{\multicolumn{2}{|c|}{$\begin{array}{l}\text { FORMACION } \\
\text { PROFESIONAL }\end{array}$}} & \multicolumn{4}{|c|}{ SER } & \\
\hline & & \multicolumn{2}{|c|}{ Profesor } & \multicolumn{2}{|c|}{ Estudiante } & \\
\hline & & $\begin{array}{l}\text { Se expresa a sí } \\
\text { mismo }\end{array}$ & $\begin{array}{l}\text { Expresa lo que } \\
\text { interpreta del } \\
\text { estudiante }\end{array}$ & $\begin{array}{l}\text { Se expresa } \\
\text { a sí mismo }\end{array}$ & $\begin{array}{l}\text { Expresa lo } \\
\text { que inter- } \\
\text { preta del } \\
\text { profesor }\end{array}$ & $\begin{array}{l}\text { Se expresa a sí } \\
\text { mismo }\end{array}$ \\
\hline REFERENTES & & $\begin{array}{l}\text { Lo que dice re- } \\
\text { alizar para la for- } \\
\text { mación del SER }\end{array}$ & $\begin{array}{l}\text { Lo que dice que } \\
\text { el estudiante re- } \\
\text { aliza }\end{array}$ & \begin{tabular}{|l|} 
Lo que dice \\
realizar para \\
la formación
\end{tabular} & $\begin{array}{l}\text { Lo que dice } \\
\text { que el pro- } \\
\text { fesor realiza }\end{array}$ & $\begin{array}{l}\text { Lo que dice re- } \\
\text { alizar para la for- } \\
\text { mación en el SA- }\end{array}$ \\
\hline $\begin{array}{l}\text { universidad } \\
\text { Profesión } \\
\text { Carrera } \\
\text { Perfil del } \\
\text { Egresado } \\
\text { Estudiante } \\
\text { Docente } \\
\text { Enseñanza- } \\
\text { aprendizaje } \\
\text { Interacción } \\
\text { docente-estu- } \\
\text { diante } \\
\text { Formación. }\end{array}$ & 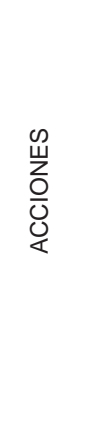 & $\begin{array}{l}\text { en relación con } \\
\text { el referente. }\end{array}$ & $\begin{array}{l}\text { mación del SER } \\
\text { en relación con el } \\
\text { referente. }\end{array}$ & $\begin{array}{l}\text { del SER en } \\
\text { relación con } \\
\text { el referente. }\end{array}$ & $\begin{array}{l}\text { para la for- } \\
\text { mación del } \\
\text { SER en rel- } \\
\text { ación con el } \\
\text { referente. }\end{array}$ & $\begin{array}{l}\text { BER en relación } \\
\text { con el referente. }\end{array}$ \\
\hline
\end{tabular}




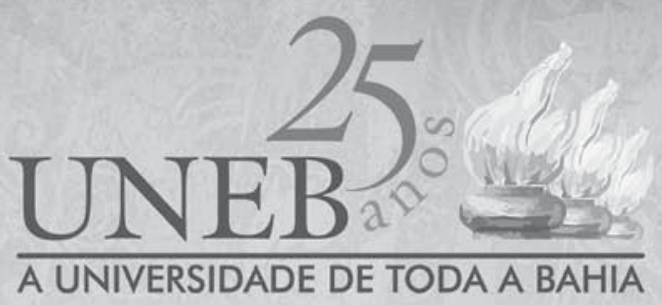

A Avaliação Institucional da UNEB tem a sua trajetória iniciada em 1998, nos parâmetros do PAIUB e prossegue utilizando os parâmetros do SINAES.

Considerando a sua estrutura multicampi, com 24 campi, localizados nas diversas regiões do Estado da Bahia e a importância da Avaliação Institucional como processo de caráter formativo e de aperfeiçoamento das atividades e finalidades da instituição, a UNEB, a partir de 2000, implantou as Comissões Setoriais de Avaliação nos 29 Departamentos, com representação dos três segmentos universitários e da sociedade civil, através de Resolução do Conselho Universitário, visando ao seu melhor funcionamento, o que tem facilitado, sobremodo, a participação mais eficaz da comunidade acadêmica.

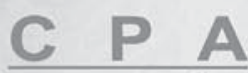

COMIS S ÃO

PRÓPRIADE

AVALIAÇÃO
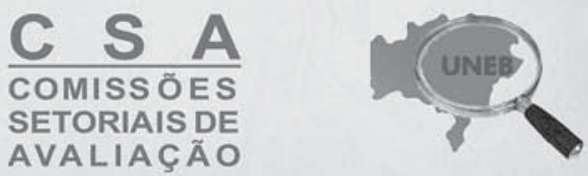